\title{
Nodal gap substance in diabetic nerve
}

\author{
K. N. SENEVIRATNE AND A. WEERASURIYA
}

From the Department of Physiology, Faculty of Medicine, University of Ceylon, Colombo 8, Ceylon (Sri Lanka)

SYNOPSIS Anoxia and $\mathrm{KCl}$ have been used to inactivate peripheral nerves by depolarization conduction block. Investigation of the inactivation patterns in isolated sciatic nerves of healthy and alloxan-diabetic rats suggests that the paranodal gap substance of healthy nerve behaves as an effective periaxonal diffusion barrier. In diabetic nerve the permeability of this barrier is significantly increased. A marked reduction in the $\mathrm{K}^{\prime}$ binding capacity of the nodal gap substance has been demonstrated in myelinated nerves of human diabetics and alloxan diabetic rats.

Several authors have observed the development of a conduction block in human peripheral nerves in limbs subject to cuff induced vascular occlusion (Magladery et al., 1950; Poole, 1956; Nathan, 1958). Seneviratne and Peiris (1969), studying the effect of hypoxia on isolated mammalian nerves, have demonstrated that the time taken for a conduction block to develop in hypoxia is about the same as the time taken for conduction block to occur during cuff induced ischaemia in human peripheral nerves. Further, Seneviratne and Peiris $(1968 a, 1969)$ have shown that the sequence of excitability change observed in human peripheral nerves during ischaemia is reproduced in isolated hypoxic rat sciatic nerves. The nerves pass through an initial phase of hyperexcitability which lasts from 2 to 10 minutes before being inactivated in 20 to 30 minutes. It has also been shown that this initial phase of hyperexcitability coincides with the period during which paraesthesiae are felt by healthy human subjects whose upper limbs are made ischaemic by vascular occlusion (Seneviratne and Peiris, 1968a). This suggests that the main factor responsible for the development of a conduction block in ischaemic nerve is nerve hypoxia, where cuff pressures slightly greater than systolic are used to occlude arterial blood flow.

Fenn and Gerschmann (1950) and Shanes (1949) have reported the leakage of intracellular $\mathrm{K}^{\prime}$ from nerve fibres during anoxia, while Shanes (1949), Huxley and Stämpfli (1951) and Adrian (1956) have shown that an increase in the external $\mathrm{K}^{\prime}$ concentration leads to a reduction of the resting membrane potential. Seneviratne and Peiris $(1969,1970)$ have suggested that this depolarization of the membrane would initially produce a lowering of its threshold and finally lead to a depolarization block. For anoxia to produce such a conduction block it is not only necessary for intracellular $\mathrm{K}^{\prime}$ to leak out, but also for this $\mathrm{K}^{\prime}$ to be held up in a periaxonal space in close proximity to the axonal surface, for it is the resulting increase of periaxonal $\mathrm{K}^{\prime}$ concentration that produces the conduction block. If the $\mathrm{K}^{\prime}$ efflux from the nerve fibre is to be held up close to the axonal surface, it is necessary to postulate the existence of a periaxonal diffusion barrier which would define the periaxonal space and limit the free diffusion of $K^{\prime}$ away from the axonal surface, thus permitting the $K^{\prime}$ concentration in this space to rise to values which are adequate to produce a depolarization of the axon.

Seneviratne and Peiris (1970) have shown that pre-treatment of healthy rat nerve with insulin increases the rate at which these nerves are inactivated by hypoxia and they account for this change in terms of the dynamics of $\mathrm{K}^{\prime}$ equilibrium in the periaxonal spaces. The critical role of the $\mathrm{K}^{\prime}$ and the periaxonal diffusion barrier in determining the rate of change of excitability in ischaemic nerve in vivo has also been demonstrated. Seneviratne et al. (1972) have shown that an acute increase in the serum $K^{\prime}$ level in the intact anaesthetized cat increases the excitability of its peripheral nerves. Cuff induced limb ischaemia leads to a more rapid inactivation of 
these nerves than in control cats, whereas release of the cuff leads to a slower rate of recovery. It was also observed that these excitability changes were maximal 30 to 60 minutes after the hyperkalaemic state had been established.

The increased resistance of the peripheral nerves of diabetic subjects to ischaemic inactivation is well documented (Steiness, 1959; Castaigne et al., 1966; Gregersen, 1968; Seneviratne and Peiris, 1968b). A similar phenomenon is seen when the isolated sciatic nerves of alloxan diabetic rats are subject to hypoxia in vitro. Seneviratne and Peiris (1969) have suggested that this resistance of diabetic nerve to ischaemic or hypoxic inactivation is due to the increased permeability of a periaxonal diffusion barrier which permits the potassium efflux to diffuse away from the axonal surface, thus delaying the build up of the $\mathrm{K}^{\prime}$ concentration which is required to depolarize the axon.

The available evidence suggests that two structures of peripheral nerve have functional diffusion barrier properties. Histological studies on the perineurium (Röhlich and Knoop, 1961; Shanthaveerappa and Bourne, 1962; Thomas, 1963; Gamble, 1964; Cravioto, 1966; Burkel, 1967; Liebermann, 1968) have shown it to consist of several laminae of closely apposed cells lined by basement membrane, the barrier properties being attributed to the 'closed contacts' or 'tight junctions' which the adjacent epithelial cells make with one another. Corresponding to these structural attributes, several workers have demonstrated that the healthy perineurium effectively retards the diffusion of a variety of substances from the extracellular fluid into the endoneurial spaces (Feng and Gerard, 1930; Bishop, 1932; Crescitelli, 1951; Lundberg, 1951 ; Krnjevic, 1954; Waggener et al., 1965; Olsson and Reese 1971; Seneviratne, 1972). A more recent concept of the role of the nodal mucopolysaccharide gap substance as a functional diffusion barrier derives from the work of Landon and Langley $(1969,1971)$. These authors have shown that the axon at the node of Ranvier is surrounded by a polyanionic mucopolysaccharide matrix which, by virtue of its cation binding properties, could limit the rate of diffusion of $\mathrm{K}^{\prime}$.

The experiments described in this study were designed to determine which of these two diffusion barriers could best account for the excitability changes observed, and to investigate the hypothesis that the excitability changes of the hypoxic diabetic nerve were determined by the increased permeability of such a barrier.

\section{METHODS}

Experimental diabetes was produced in six month old male rats weighing between 125 and $200 \mathrm{~g}$ by a modification of the method described by Klebanoff and Greenbaum (1954). A single dose of alloxan monohydrate (BDH) of $15 \mathrm{mg} / 100 \mathrm{~g}$ body weight in freshly prepared $0.0125 \mathrm{M}$ citrate-phosphate buffer at $\mathrm{pH} 4.0$ was injected intraperitoneally at a concentration of $10 \mathrm{mg} / \mathrm{ml}$ and the rats maintained in separate metabolism cages with free access to food and water. The criteria used to establish diabetes in these animals were a blood glucose level of over $200 \mathrm{mg} / 100 \mathrm{ml}$ and a glycosuria of $1 \%$ or more. These animals were maintained for at least two weeks in this condition before being used for study. The duration of the diabetic state in the animals studied varied from two to five weeks. Litter mates of these rats were maintained under the same conditions and served as controls in all the experiments described below.

ELECTROPHYSIOLOGICAL EXPERIMENTS The rats were anaesthetized with intraperitoneal sodium pentobarbitone (Nembutal) $50 \mathrm{mg} / \mathrm{kg}$ body weight and the sciatic nerves were dissected out rapidly from the level of the sciatic notch to the gastrocnemius tendon. The nerves were cleaned of fat, connective tissue, and blood vessels. In some experiments the nerve trunk was desheathed by stripping off the perineurium. The tibial component of the sciatic nerve was mobilized at the root of the thigh by separating it from its common peroneal and sural branches laterally and the sciatic trunk proximally. The segment of tibial nerve extending up to the gastrocnemius tendon was removed by snipping off the branches originating at the knee. The proximal segment of the tibial nerve which consists of a single fascicle was desheathed under a binocular dissecting microscope using fine watchmaker's forceps. The sheath was gently rolled down along the length of the single fascicle of the tibial nerve and then continued downwards to desheath the medial and lateral plantar nerves which originate from the tibial nerve. The splaying out of individual nerve fibres from the surface of the nerve trunk when the desheathed nerves were immersed in Locke's solution before the experiment was recognized as a reliable 
guide to the completeness of the desheathing. Occasionally, nerves were examined histologically to verify the reliability of the desheathing technique. The nerve was then mounted in a small moist nerve chamber provided with an inlet tube and an outlet tube containing a valve which maintained a one-way gas flow. The nerve lay across platinum stimulating, earth and recording electrodes, so that the proximal end of the nerve lay across the stimulating electrodes and the distal cut end of the nerve lay on the distal recording electrode. The chamber was then made gas-tight by replacing its lid and sealing it with Vaseline. The gas mixtures used in the experiments are described under the respective experiments. The gases were admitted at a constant rate of flow into the nerve chamber after bubbling it through a wash bottle containing Locke's solution which was maintained at $37^{\circ} \mathrm{C}$.

The nerve was stimulated using square-wave electric stimuli of $0.01 \mathrm{~ms}$ duration and variable voltage from a Grass S4 stimulator and an RF coupled isolating transformer. The evoked responses were amplified by a Grass P511R RC coupled preamplifier with half-amplitude frequencies of $7 \mathrm{~Hz}$ and $2 \mathrm{KHz}$. The amplified responses were monitored through a loud-speaker and displayed on one beam of a Tektronix 502 oscilloscope, the sweep of which was triggered by the stimulator output with negligible delay. The lower beam of the oscilloscope monitored the stimulus through a high impedance probe. Single sweeps of the oscilloscope were photographed on $35 \mathrm{~mm}$ film.

SERIES 1 These experiments were designed to investigate the effects of desheathing on the anoxic inactivation patterns of normal and diabetic nerves. Control experiments were performed to assess the degree of functional change that desheathing may have had on these nerves.

The desheathed nerves of healthy and diabetic rats were mounted in the chamber and maintained in an atmosphere of $95 \% \quad \mathrm{O}_{2}+5 \% \mathrm{CO}_{2}$. The evoked response to a maximal stimulus was observed and the stimulus reduced in size until the evoked response was reduced to $50 \%$ of its maximal size. This stimulus was maintained constant and the responses to it monitored at five minute intervals for 40 minutes during exposure to the gas mixture.

Sheathed and desheathed nerves of healthy and diabetic rats were studied in a similar manner during exposure to an anoxic gas mixture. These nerves were mounted in the nerve chamber and first exposed to a gas mixture containing $95 \% \mathrm{O}_{2}+5 \% \mathrm{CO}_{2}$ during which time the stimulus size required to produce an evoked response which was $50 \%$ of the maximum was determined. The nerves were then exposed to the anoxic gas mixture $\left(95 \% \mathrm{~N}_{2}+5 \% \mathrm{CO}_{2}\right)$ and the evoked responses to this submaximal stimulus of constant size recorded at five minute intervals for 30 minutes.

The experiments described in this series, where sheathed and desheathed nerves of healthy and diabetic rats were studied during exposure to gas mixtures containing or devoid of oxygen, were done alternately to ensure that comparable experimental conditions were maintained between experiments.

SERIES 2 The permeability of the perineurial sheath of healthy and diabetic nerves was investigated by observing the size of the evoked nerve response while short lengths of the intact nerve were immersed in a gel which contained a Locke $+60 \mathrm{mM} \mathrm{K}$ solution.

The intact nerve of the healthy or diabetic rat was mounted in the nerve chamber with a $20 \mathrm{~mm}$ length of nerve between stimulating and recording electrodes lying within a small earthed silver trough which held a $0.75 \%$ agar gel made up in a Locke $+60 \mathrm{mM} \mathrm{\textrm {K } ^ { \prime }}$ solution. The chamber was sealed and exposed to a $95 \% \mathrm{O}_{2}+5 \% \mathrm{CO}_{2}$ gas mixture. The response to a maximum stimulus was monitored at five minute intervals for 40 minutes.

SERIES 3 The permeability of the nodal gap substance to $\mathrm{K}^{\prime}$ was studied in this series. Desheathed normal and diabetic nerves were immersed in a gel containing a Locke $+20 \mathrm{mM} \mathrm{K} \mathrm{K}^{\prime}$ solution and the evoked responses of these nerves studied while they were maintained in a $95 \% \mathrm{O}_{2}+5 \% \mathrm{CO}_{2}$ gas mixture.

Control experiments were first performed in which desheathed normal and diabetic nerves were maintained in oxygen in the chamber while lengths of the nerve lay immersed in a $0.75 \%$ agar solution made up in Locke $+20 \mathrm{mM} \mathrm{NaCl}$ contained within the earthed silver trough.

SERIES 4 These experiments were designed to investigate the effects of filling the endoneurial spaces of desheathed nerves with solutions of Locke or Locke $+5 \mathrm{mM} \mathrm{KCl}$ on the rate of anoxic inactivation of these nerves.

Desheathed nerves of healthy or diabetic rats were immersed for 30 minutes in Locke's solution kept aerated with a gas mixture of $95 \% \mathrm{O}_{2}+5 \% \mathrm{CO}_{2}$. The nerves were then mounted in the chamber and exposed to a gas mixture of $95 \% \mathrm{~N}_{2}+5 \% \mathrm{CO}_{2}$, and the responses evoked by a constant stimulus of submaximal strength monitored for 30 minutes. After one nerve of the animal had been studied in this manner the parallel nerve was desheathed and immersed for the same duration in a Locke+ $5 \mathrm{mM} \mathrm{K}$ solution, after which it was mounted in the chamber and made anoxic. The responses evoked by 
a submaximal stimulus during this period were monitored for 30 minutes.

HISTOLOGY The $\mathrm{K}^{\prime}$ binding capacity of the nodal mucopolysaccharide gap substance of diabetic and healthy nerves was studied by the method of Landon and Langley (1971). Sciatic nerves from diabetic and healthy rats were fixed for 24 hours in $10 \%$ formalin, the perineurial sheath being removed after two hours of fixation. After fixation the nerves were washed in distilled water and the $\mathbf{K}^{\prime}$ binding accomplished by immersing the nerves in a $0 \cdot 1 \mathrm{M} \mathrm{KCl}$ solution for 60 minutes. Subsequently the nerve was washed again in distilled water and the bound $\mathrm{K}^{\prime}$ localized with freshly prepared ice cold $1 \mathrm{M}$ sodium cobaltinitrite and converted to the black cobalt sulphide by immersion in a $10 \%$ solution of dilute aqueous ammonium sulphide. The fixed and stained nerves were left in $50 \%$ glycerine for 24 hours. Single fibres were teased apart with fine needles and mounted in $30 \%$ glycerine for light microscopy.

Single fibres from 20 diabetic and 15 healthy rats were studied by this method, together with three healthy human sural nerves removed during amputations of the lower limbs and six sural nerve biopsies from human subjects with established diabetes mellitus.

\section{RESULTS}

SERIES 1 Six healthy and six diabetic nerves were desheathed and maintained in $95 \% \mathrm{O}_{2}+$

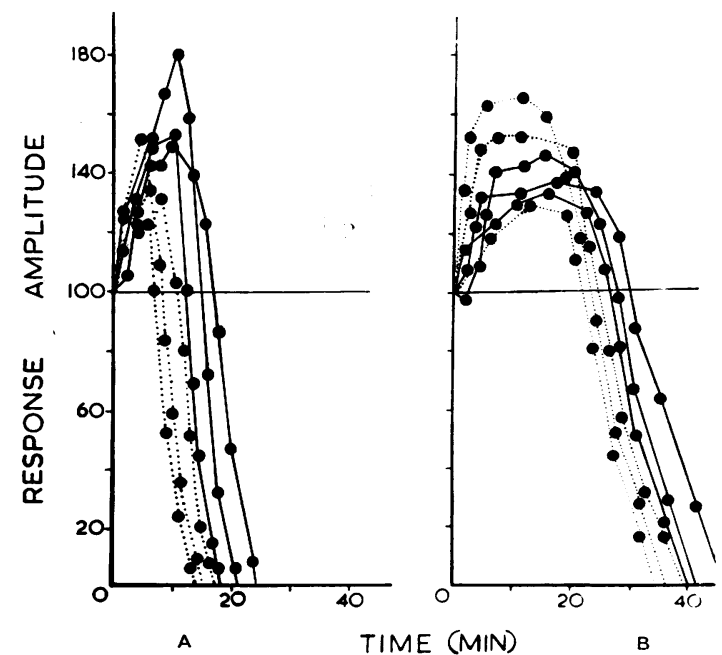

FIG. 1. Inactivation of sheathed nerves $(\longrightarrow)$ and desheathed nerves $(\cdots)$ in anoxia; (A) healthy nerves, and $(\mathrm{B})$ diabetic nerves.

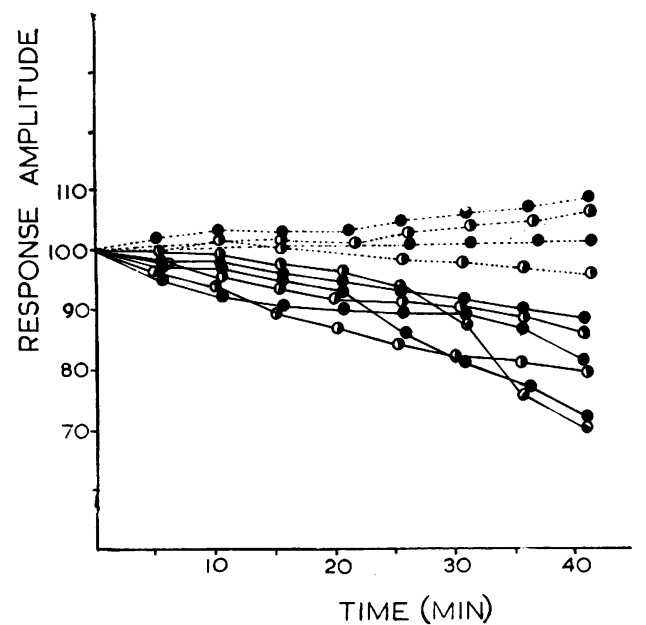

FIG. 2. Inactivation of sheathed nerves in oxygen during immersion in Locke+60 $\mathrm{mM}$ solutions. Healthy nerves (O) and diabetic nerves (O); in Locke $+60 \mathrm{mM} \mathrm{KCl}(-)$ and control experiments in Locke + $60 \mathrm{mM} \mathrm{NaCl}(\cdots)$.

$5 \% \mathrm{CO}_{2}$. During the 40 minute period of observation the maximum variation in evoked response size was $13 \%$ of its initial value. The range of response amplitude variation was 5$13 \%$ with a mean value of $9 \%$.

The nerves of 10 healthy rats were studied during inactivation by anoxia.'Ten of the nerves

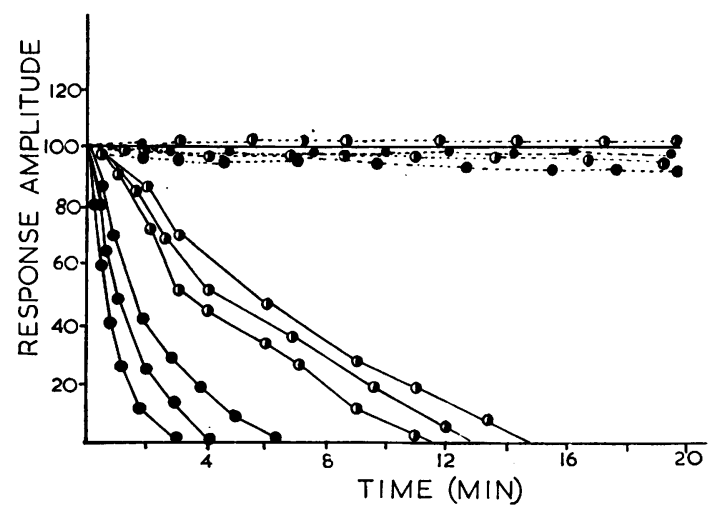

FIG. 3. Inactivation of desheathed nerves in oxygen during immersion in Locke+20 $\mathrm{mM}$ solutions. Healthy nerves (O) and diabetic nerves (O), in Locke $+20 \mathrm{mM} \mathrm{KCl}(-)$ and control experiments in Locke+ $20 \mathrm{mM} \mathrm{NaCl}(\cdots)$. 


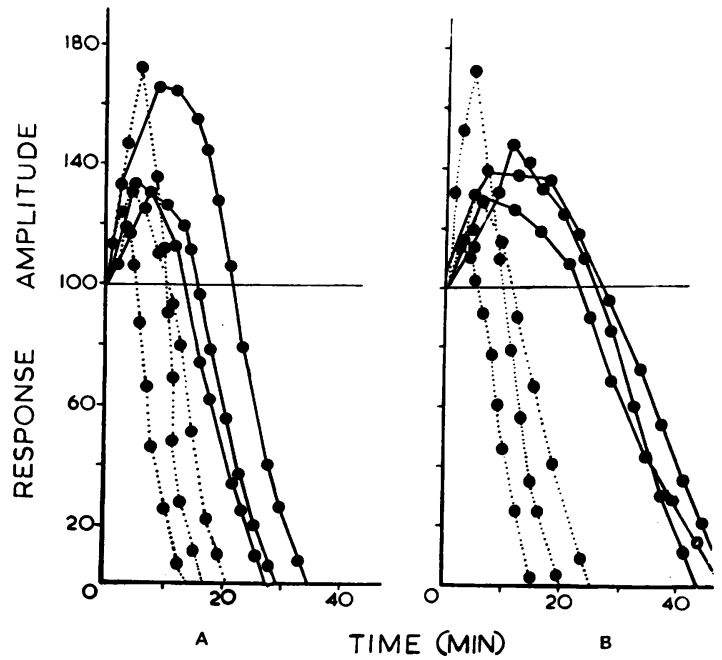

FIG. 4. Inactivation of desheathed nerves in anoxia after immersion in Locke's solution (-) and Locke $+5 m M K^{\prime}(\cdots)$ (A) healthy nerves and (B) diabetic nerves.

were exposed to the gas mixture in a desheathed state while 10 were studied with the sheath intact. The nerves of 10 diabetic rats were studied in a similar manner and the results obtained for three sets of healthy and diabetic nerves are presented in Fig. 1A and B. It is evident that desheathing enhances the rate of anoxic inactivation of both healthy and diabetic nerves.

Table 1 presents an analysis of the results obtained with the healthy and diabetic nerves, a comparison being made between the times taken for the nerves to regain resting levels of excitability after the hyperexcitable phase, and the times taken for the nerves to reach a level of excitability equal to $30 \%$ of their resting values. It is seen that the rate of anoxic inactivation of diabetic nerve is slower than that of healthy nerve and that desheathing increases the rate of inactivation of both sets of nerves. There is however no significant difference between the reduction of inactivation times of healthy and diabetic nerves produced by desheathing them.

SERIES 2 The results of experiments in which sheathed healthy and diabetic nerves were maintained in oxygen while immersed in a solution containing Locke $+60 \mathrm{mM} \mathrm{KCl}$ in agar show that the reduction of response amplitude after 40 minutes varied from $70-87 \%$ of the resting value in the healthy nerves and from $70-91 \%$ in the diabetic nerves. The results obtained from six nerves are presented in Fig. 2, while Table 2 analyses the results obtained from the 10 normal and 10 diabetic nerves studied in this series. The lack of a significant difference between these results indicates that the perineurial barrier of the diabetic nerve is as effective in retarding the diffusion of the $60 \mathrm{mM} \mathrm{KCl}$ from the surface of the sheathed nerve to the endoneurial space as is the perineurium of the healthy nerve.

Results of control experiments in which diabetic and healthy nerves were immersed in a Locke $+60 \mathrm{mM} \mathrm{NaCl}$ solution indicate that the depression of function seen in the $\mathrm{KCl}$ experiments is likely to be due to the specific depolarizing action of the $K^{\prime}$ rather than to at non-specific osmolarity effect due to the use of $60 \mathrm{mM}$ solutions.

SERIES 3 In this series desheathed healthy and diabetic nerves maintained in oxygen were immersed in a Locke $+20 \mathrm{mM} \mathrm{KCl}$ solution Some of the results obtained are depicted in Fig. 3, while Table 3 makes a comparative analysis of the results obtained with the 10 healthy and 10 diabetic nerves of this series. It is seen that under these conditions diabetic nerves are inactivated far more rapidly than are the healthy ones. In this experiment, too, control studies were made by immersing the desheathed nerves in a Locke $+20 \mathrm{mM} \mathrm{NaCl}$ solution to establish the fact that the inactivation of nerves achieved by increasing the concentration of the $\mathrm{K}^{\prime}$ in the endoneurial space was due to the specific depolarizing action of the $\mathrm{K}^{\prime}$ rather to a non-ion-specific osmotic effect.

SERIES 4 These experiments were designed to determine the additive effect that a $\mathrm{K}^{\prime}$ efflux from the axon produced by anoxia would have on inactivation time when the endoneurial spaces of the desheathed nerve had been previously filled with Locke's solution or a Locke + $5 \mathrm{mM} \mathrm{K}$ solution. The results of this series of experiments are presented in Fig. 4 and Table 4. They reveal that both healthy and diabetic nerves 
TABLE 1

INACTIVATION TIMES OF SHEATHED AND DESHEATHED NERVES IN ANOXIA

\begin{tabular}{|c|c|c|c|c|c|c|c|}
\hline & \multicolumn{3}{|c|}{ Healthy nerves } & \multicolumn{3}{|c|}{ Diabetic nerves } & \multirow{2}{*}{$\begin{array}{c}\text { Significance of } \\
\text { difference between } \\
t_{1} \text { and } t_{2} \\
\text { (Student's t test) }\end{array}$} \\
\hline & $\begin{array}{l}\text { Sheathed } \\
N=10\end{array}$ & $\begin{array}{l}\text { Desheathed } \\
\quad N=10\end{array}$ & $\begin{array}{l}\text { Change } \\
\quad\left(t_{1}\right)\end{array}$ & $\begin{array}{c}\text { Sheathed } \\
N=10\end{array}$ & $\begin{array}{l}\text { Desheathed } \\
\quad N=10\end{array}$ & $\begin{array}{l}\text { Change } \\
\left(t_{2}\right)\end{array}$ & \\
\hline $\begin{array}{l}\text { Mean time to regain resting excitability } \\
\text { (min) } \\
\text { Range of variation ( } \mathrm{min} \text { ) }\end{array}$ & $\begin{array}{c}15 \cdot 5 \\
(12-18)\end{array}$ & $\begin{array}{c}10 \cdot 2 \\
(7-12)\end{array}$ & $5 \cdot 3$ & $\begin{array}{c}29 \cdot 4 \\
(24-32)\end{array}$ & $\begin{array}{c}23 \cdot 5 \\
(20-26)\end{array}$ & 5.9 & $\begin{array}{c}P \text { is greater than } 0 \cdot 10 \\
\text { NS }\end{array}$ \\
\hline $\begin{array}{l}\text { Mean time to reach } 30 \% \text { of resting } \\
\text { excitability (min) } \\
\text { Range of variation (min) }\end{array}$ & $\begin{array}{c}20 \cdot 1 \\
(17-23)\end{array}$ & $\begin{array}{c}14 \cdot 4 \\
(12-17)\end{array}$ & $5 \cdot 7$ & $\begin{array}{c}37 \cdot 5 \\
(34-41)\end{array}$ & $\begin{array}{c}32 \cdot 1 \\
(29-35)\end{array}$ & $5 \cdot 4$ & $\begin{array}{c}P \text { is greater than } 0 \cdot 10 \\
\text { NS }\end{array}$ \\
\hline
\end{tabular}

TABLE 2

INACTIVATION OF SHEATHED NERVES IN LOCKE $+60 \mathrm{mM} \mathrm{KCl} \mathrm{IN} \mathrm{OXYGEN}$

\begin{tabular}{|c|c|c|c|}
\hline & $\begin{array}{l}\text { Healthy nerves } \\
\quad(N=10)\end{array}$ & $\begin{array}{l}\text { Diabetic nerves } \\
\quad(N=10)\end{array}$ & $\begin{array}{c}\text { Significance of difference } \\
\text { (Student's t test) }\end{array}$ \\
\hline $\begin{array}{l}\text { Mean response amplitude } \\
\text { at } 20 \text { th minute }(\%) \\
\text { Range of variation }\end{array}$ & $\begin{array}{c}93 \\
(85-97)\end{array}$ & $\begin{array}{c}91 \\
(90-97)\end{array}$ & $\begin{array}{c}P \text { is greater than } 0 \cdot 1 \\
\text { NS }\end{array}$ \\
\hline $\begin{array}{l}\text { Mean response amplitude } \\
\text { at } 40 \text { th minute }(\%) \\
\text { Range of variation }\end{array}$ & $\begin{array}{c}81 \\
(70-85)\end{array}$ & $\begin{array}{c}83 \\
(70-87)\end{array}$ & $\begin{array}{c}P \text { is greater than } 0 \cdot 1 \\
\text { NS }\end{array}$ \\
\hline
\end{tabular}

TABLE 3

INACTIVATION OF DESHEATHED NERVES IN LOCKE $+20 \mathrm{mM} \mathrm{KCl} \mathrm{IN} \mathrm{OXYGEN}$

\begin{tabular}{|c|c|c|c|}
\hline & $\begin{array}{c}\text { Healthy nerves } \\
\quad N=10\end{array}$ & $\begin{array}{l}\text { Diabetic nerves } \\
\quad N=10\end{array}$ & $\begin{array}{l}\text { Significance of difference } \\
\text { (Student's t test) }\end{array}$ \\
\hline $\begin{array}{l}\text { Mean response amplitude at } \\
1 \text { st minute }(\%) \\
\text { Range of variation }\end{array}$ & $\begin{array}{c}91 \cdot 5 \\
(70-98)\end{array}$ & $\begin{array}{c}43 \cdot 7 \\
(29-89)\end{array}$ & $P$ is less than 0.001 \\
\hline $\begin{array}{l}\text { Mean response amplitude at } \\
\text { 3rd minute }(\%) \\
\text { Range of variation }\end{array}$ & $\begin{array}{c}59 \cdot 1 \\
(29-92)\end{array}$ & $\begin{array}{c}12 \cdot 0 \\
(3-37)\end{array}$ & $\mathrm{P}$ is less than 0.001 \\
\hline
\end{tabular}

TABLE 4

INACTIVATION OF DESHEATHED NERVES IN LOCKE'S OR LOCKE $+5 \mathrm{mM} \mathrm{KCl} \mathrm{IN} \mathrm{ANOXIA}$

\begin{tabular}{|c|c|c|c|c|c|c|c|}
\hline & \multicolumn{3}{|c|}{ Healthy nerves } & \multicolumn{3}{|c|}{ Diabetic nerves } & \multirow{2}{*}{$\begin{array}{c}\text { Significance of } \\
\text { difference between } \\
t_{1} \text { and } t_{2}\end{array}$} \\
\hline & $\begin{array}{l}\text { In Locke } \\
\quad N=10\end{array}$ & $\begin{array}{c}\text { In Locke+ } \\
5 m M K^{\prime} \\
N=10\end{array}$ & $\begin{array}{c}\text { Change } \\
t_{1}\end{array}$ & $\begin{array}{c}\text { In Locke } \\
N=10\end{array}$ & $\begin{array}{l}\text { Locke+ } \\
5 m M K^{\prime} \\
N=10\end{array}$ & $\begin{array}{c}\text { Change } \\
t_{2}\end{array}$ & \\
\hline $\begin{array}{l}\text { Mean time to regain resting excitability } \\
\text { (min) }\end{array}$ & $14 \cdot 3$ & $7 \cdot 9$ & $6 \cdot 4$ & $19 \cdot 3$ & $8 \cdot 4$ & $10 \cdot 9$ & $P$ is less than 0.01 \\
\hline $\begin{array}{l}\text { Range of variation (min) } \\
\text { Mean time to reach } 30 \% \text { in resting }\end{array}$ & $(11-22)$ & $(4-11)$ & & $(14-24)$ & $(7-11)$ & & \\
\hline $\begin{array}{l}\text { excitability (min) } \\
\text { Range of variation (min) }\end{array}$ & $\begin{array}{c}21 \cdot 2 \\
(18-29)\end{array}$ & $\begin{array}{c}12 \cdot 3 \\
(10-17)\end{array}$ & $8 \cdot 9$ & $\begin{array}{c}31 \cdot 9 \\
(17-35)\end{array}$ & $\begin{array}{c}16 \cdot 0 \\
(14-20)\end{array}$ & $15 \cdot 9$ & $P$ is less than 0.001 \\
\hline
\end{tabular}




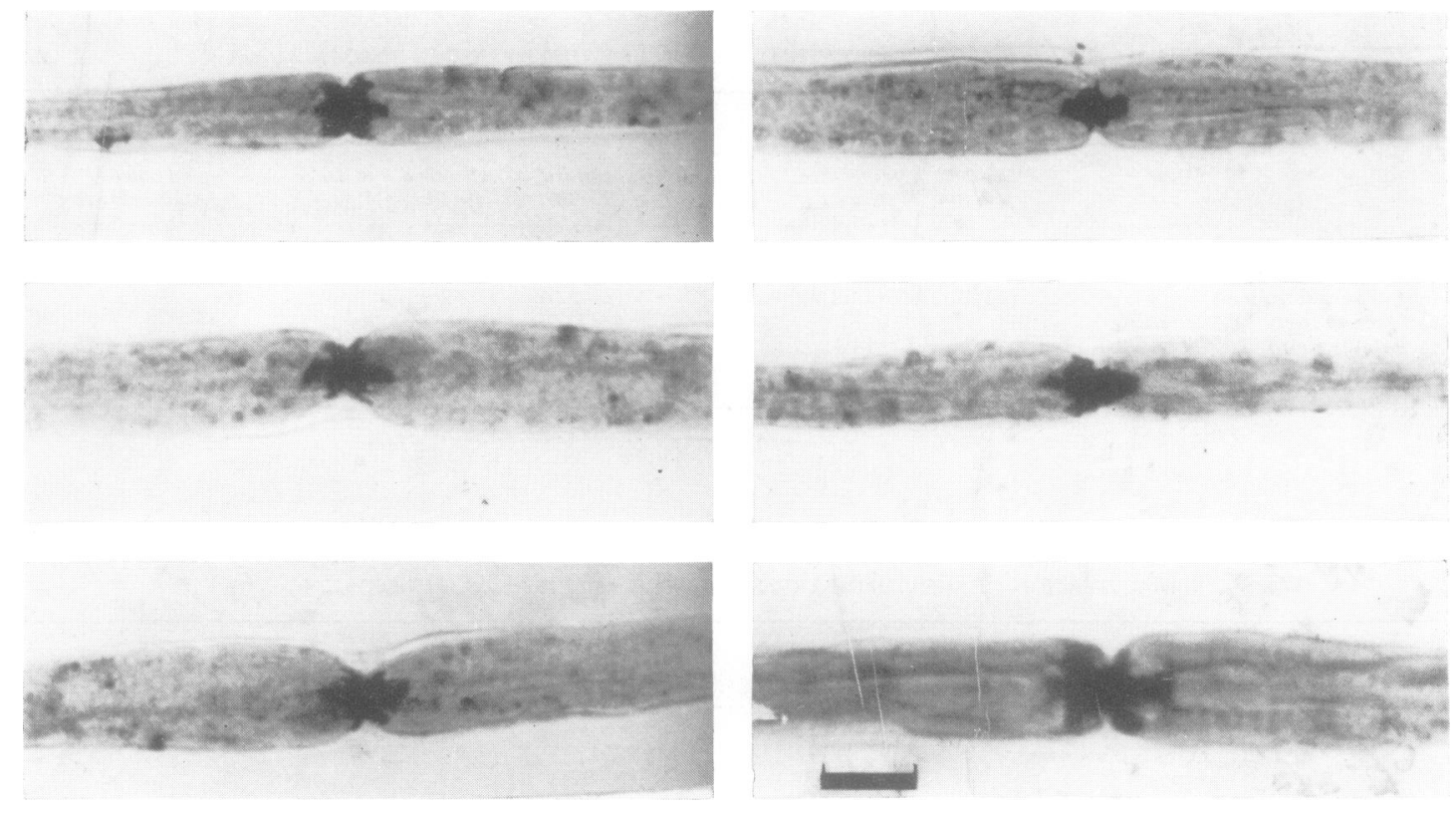

FIG. 5. Single myelinated nerve fibres stained to demonstrate $K^{\prime}$ binding by the gap substance at the node $\stackrel{\$}{\Omega} \mathrm{N}$ Fibres from sciatic nerve of healthy rat on the left. and healthy human sural nerve on the right. Scale: $10 \mu m \stackrel{ }{\circ}$ 을
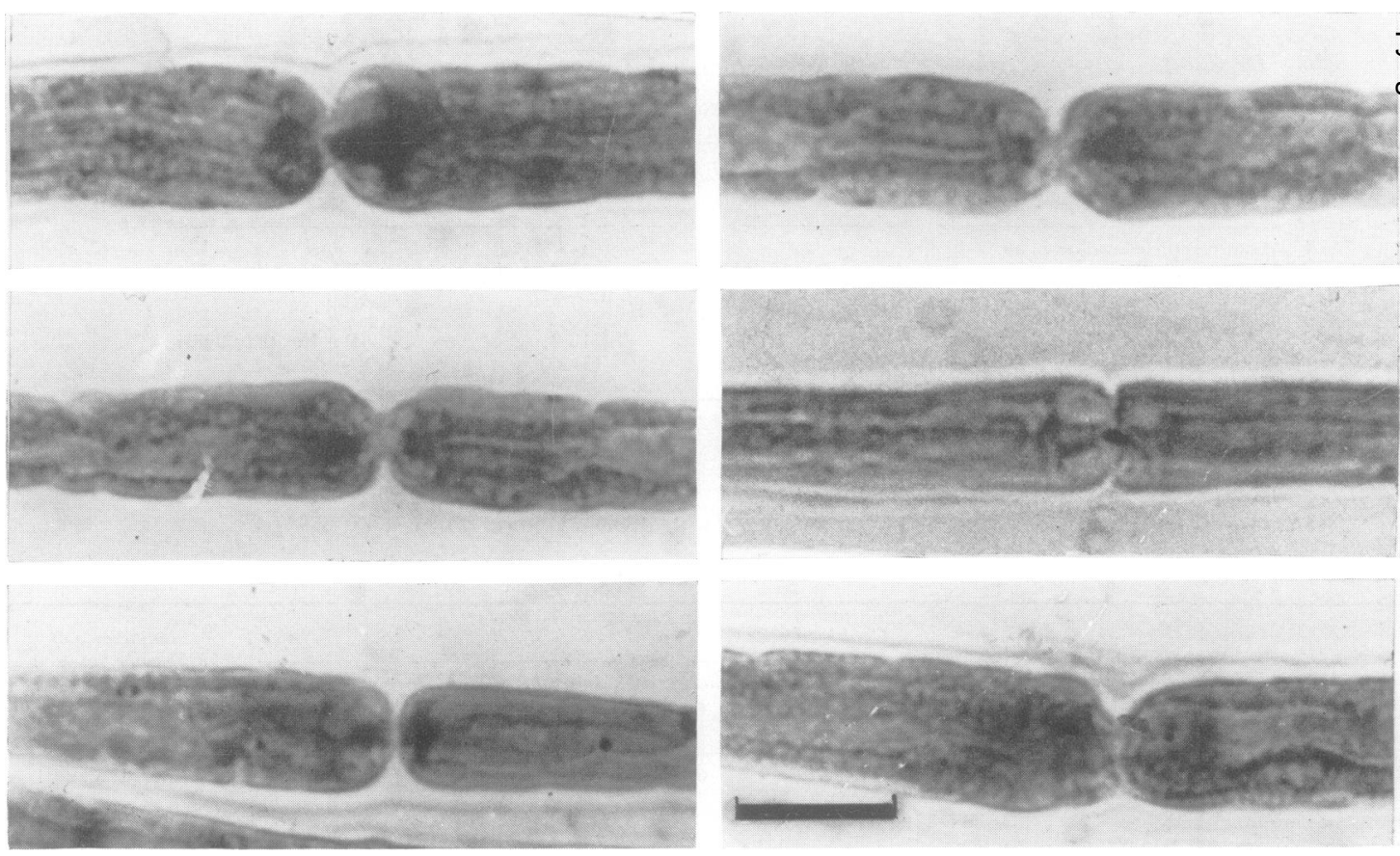

FIG. 6. Diabetic nerve fibres stained to demonstrate $K^{\prime}$ binding. Fibres from sciatic nerves of alloxan diabetic rats on the left and from sural nerves of human diabetics on the right. Scale: $10 \mu \mathrm{m}$. 
show a significant reduction of their anoxic inactivation times when the endoneurial spaces contain the Locke $+5 \mathrm{mM} \mathrm{KCl}$ rather than Locke's solution. Although both sets of nerves exhibit a reduction of inactivation time, the results show that the acceleration of the inactivation process in the diabetic nerve is significantly greater than that seen in the healthy nerve.

HISTOLOGY The results obtained with healthy human and rat nerve confirm the observations of Landon and Langley (1971). Figure 5A shows the nodal gap filled by an amorphous dense black matrix extending onto the surface of the adjacent paranodal myelin sheath. In some fibres the entire length of the internodal myelin could be seen covered with a very delicate layer of this black staining substance which, accumulating within the incisures of the SchmidtLanterman clefts, outlined these funnel shaped invaginations clearly. In marked contrast, several of the nodes seen in diabetic nerves, both rat and human (Fig. 5B), showed a distinct reduction in $\mathrm{K}^{\prime}$ binding and nodal staining, and in several the axon passing between the adjacent myelin sheaths could be clearly visualized. In the diabetic nerves a continuous spectrum of variation in the amount of this $\mathrm{K}^{\prime}$ binding could be demonstrated, some nodes appearing completely normal in this respect while adjacent nodes were partially or completely devoid of the bound $\mathrm{K}^{\prime}$ ion (Fig. 6). Multi-fibre preparations of diabetic nerves showed that this abnormality of nodal staining was patchy in its distribution along the length of the nerve trunk. Some areas of nerve showed nodes which stained completely normally, while in adjacent areas the majority of the nodes exhibited the characteristic staining defect. Even within such an area the nodal changes were not uniform, some nodes showed a complete absence of $\mathrm{K}^{\prime}$ staining, while others showed intermediate stages of the defect. When these staining changes occurred in the larger diameter myelinated fibres they were more conspicuous than similar changes occurring in the thinner myelinated fibres. A statistically significant comparison of the extent of staining changes between diabetic nerves could not be made because of the patchy nature of the distribution of this staining abnormality. Some of the diabetic fibres showed the nodal widening, paranodal swelling, and myelin changes which are characteristic of the early phase of segmental demyelination. It was evident, however, that the reduction in $\mathrm{K}^{\prime}$ binding at the nodes was a much more extensive process, in that a complete absence of $\mathrm{K}^{\prime}$ binding could be demonstrated at several nodes where the morphology of the node and myelin appeared completely normal.

\section{DISCUSSION}

The results of experiments of series 1 establish the fact that the perineurium of the diabetic nerve is as effective a barrier to the diffusion of nitrogen as is the perineurium of healthy nerve, while the results of the experiments of series 2 demonstrate the unimpaired barrier property of the diabetic perineurium with respect to the diffusion of $60 \mathrm{mM} \mathrm{KCl}$. It is however evident from Fig. 1 that the desheathed nerves in anoxia show the characteristic phase of hyperexcitability before the onset of inactivation, though now with shorter time constants than before. The perineurium is hence unlikely to be the diffusion barrier which is responsible for the production of the sequence of excitability changes seen in anoxic or ischaemic nerve. This conclusion reinforces the one derived from theoretical considerations. Thus it is known that extracellular $\mathrm{K}^{\prime}$ concentrations of the order of $10-20 \mathrm{mEq} / \mathrm{l}$. are required to produce a depolarization block of excitable cells, while the $\mathbf{K}^{\prime}$ efflux from an anoxic myelinated nerve is in the picomole range (Hodgkin, 1964), thus setting limits to the dimensions of the hypothetical periaxonal space defined by the barrier in the nanomicron range. Similar considerations enabled Frankenhaeuser and Hodgkin (1956) to define the dimensions of the periaxonal space between the squid axon and its Schwann cell at approximately $20 \mathrm{~nm}$, while Kuffler et al. (1966) estimate that the space between the neural and glial membranes in the optic nerve of Necturus is about $15 \mathrm{~nm}$.

The results of experiments of series 3 indicate that the desheathed diabetic nerves immersed in a Locke $+20 \mathrm{mM} \mathrm{KCl}$ solution and maintained in oxygen are depolarized far more rapidly than healthy nerves under comparable conditions. These observations lend support to the concept of the presence of a relatively impermeable ionic periaxonal barrier in healthy myelinated 
nerve. Such a barrier must be sited in very close proximity to the bare axon at the node of Ranvier, this being the only functional site concerned with active ion exchange and passage of a membrane current. It is argued that the faster inactivation of diabetic nerve seen under these conditions is due to the increased permeability of the diffusion barrier. Desheathing permits the $25 \mathrm{mM} \mathrm{KCl}$ of the bathing solution to diffuse into and fill the endoneurial spaces. In the diabetic nerve, the defective barrier permits this high $\mathrm{K}^{\prime}$ solution in the endoneurial space to gain rapid access to the nodal axon and produce a conduction block by depolarizing it. In contrast, inactivation of the healthy nerve is delayed by the presence of a functional barrier which effectively impedes the diffusion of $\mathrm{K}^{\prime}$ from the endoneurial space to the surface of the nodal axon.

The results of experiments of series 4 lend further support to the hypothesis that the excitability changes seen in anoxic nerve are determined primarily by the depolarization effects produced by $\mathrm{K}^{\prime}$ concentrations in a periaxonal space, the rate and extent of inactivation being determined by the dynamics of the $\mathrm{K}^{\prime}$ in this space. Since the space is defined by the periaxonal diffusion barrier, it is argued that the rate of change of excitability is determined by the permeability of this barrier to $\mathrm{K}^{\prime}$.

The experiments of series 4 were designed to investigate this hypothesis, by comparing the responses of healthy and diabetic nerve during anoxia. Desheathed nerves were first immersed in a Locke or Locke $+5 \mathrm{mM} \mathrm{KCl}$ solution to allow this solution to fill the endoneurial spaces. When exposed to nitrogen the nerves immersed in the Locke $+5 \mathrm{mM} \mathrm{KCl}$ were inactivated much faster than the nerves immersed in Locke's solution. Although the rate of inactivation of both healthy and diabetic nerves is hastened by immersion in the Locke+5 $\mathrm{mM} \mathrm{KCl}$, the acceleration of this process in the diabetic nerve is significantly greater than that of healthy nerve. It is argued that this is due to the fact that immersion in Locke $+5 \mathrm{mM} \mathrm{K}^{\prime}$ increases the resting level of excitability of the diabetic nerve. The defective diffusion barrier of the nerve allows the Locke $+5 \mathrm{mM} \mathrm{K}^{\prime}$ to reach the axon and produce an initial depolarization, whereas the functional barrier of the healthy nerve restricts the entry of $\mathrm{K}^{\prime}$ and maintains the excitability of the axon at or near resting levels. When these nerves are now made anoxic, the $\mathrm{K}^{\prime}$ efflux from the axon provides an additional input of this ion into the periaxonal space. In the diabetic nerve, this supplements the initial depolarization produced by immersion in the Locke $+5 \mathrm{mM} \mathrm{K}$, hence the level of depolarization required to achieve conduction block is soon reached. In the healthy nerve, however, the impermeability of the diffusion barrier maintains the axon at or near resting levels of excitability despite immersion in the Locke $+5 \mathrm{mM} \mathrm{KCl}$ and conduction block is reached only when the anoxic fibre has provided the periaxonal space with enough $\mathrm{K}^{\prime}$ to depolarize it from resting to inactivation levels.

The histological evidence obtained in this study provides a structural identity to the diffusion barrier, the diabetic nerves showing changes in staining properties which parallel the functional changes of this barrier postulated on the basis of electrophysiological evidence? Landon and Langley $(1969,1971)$ and Langleya (1969), have described the histochemistry of the paranodal gap substance. At the nodes the bare axons are surrounded by a 'cementing disc (Hess and Young, 1952) which Landon and Langley (1971) describe as being composed predominantly of protein linked carboxylated mucopolysaccharides. Their histochemical studies of ion exchange at the node have demonstrated the behaviour of this mucopolysaccharide as a fixed polyanionic charged matrix. On the basis of their investigations of the cation binding property of this matrix with electron microscopic fine structural localization, they have suggested that polyanions containing carboxyl groups, or possibly a mixture containing carboxyl and phosphate groups with the carboxylated polyanions predominating, are present in the region of the node, and that these polyanions are responsible for the greater part of the cation binding. They have also suggested that 'the presence of such a polyanionic matrix might limit the diffusion of the $\mathrm{K}^{\prime}$ which leaves the axon during the passage of an impulse and hold it available for redistribution across the nodal axolemma during its return to the active state'.

The striking similarity of the chemical composition of the gap substance as deduced from 
its staining properties to basement membrane material and its apparent morphological continuity with the basement membrane substance as evidenced by the electron micrographs of Landon and Langley (1971) suggest that this gap substance represents an accumulation of Schwann cell basement membrane material. The greater deposition of this material at the node rather than along the surface of the Schwann cell in the internodal region is likely to be determined by the fact that the paranodal region of the Schwann cell contains large numbers of mitochondria and microvilli which are characteristic features associated with sites of active transcellular transport mechanisms. The basement membrane is an amorphous matrix secreted by epithelial cell layers and is composed of linear macromolecules of protein linked mucopolysaccharides forming simple or branched chains whose significant physical characteristics are length, charge, density, and molecular volume. Schubert (1964) has suggested that in the native state these protein-polysaccharide units are diffuse molecules in contrast with the more compact protein molecules such as those of albumin, and that the domain of a diffuse molecule may be thousands of times larger than that indicated by its atomic volume. When present in higher concentrations the domains of these molecules interpenetrate and result in chain entanglements and long range coupling. It is believed that the arrangement and density of these charged molecules determine the permeability of the basement membrane to the passage of macromolecules and solvents through its substance. The highly charged and highly hydrated molecular matrix impedes the flow of water and tends to exclude other macromolecules from its domain. The many negative charges of the matrix derived from its hyaluronate component also have the capacity to immobilize cations such as $\mathrm{Na}^{\prime}, \mathrm{Ca}^{\prime \prime}$, and $\mathrm{K}^{\prime}$. There is good evidence that matrices composed of these protein mucopolysaccharides networks effectively retard the passage of molecules through it by virtue of their 'sieving' effects (Laurent and Pietruszkiewicz, 1961; Laurent and Ogston, 1963) and by exhibiting an 'exclusion' phenomenon (Ogston and Phelps, 1961). Whereas these barrier properties of the mucopolysaccharide complexes to macromolecules are due to steric relationships between these molecules, there is some evidence that the distribution of polyanions in the matrix can influence the passage and distribution of cations through it. Biochemical and electron microscopic histochemistry show that mucopolysaccharides present on the surface of the sarcoplasmic reticulum of muscle have a striking capacity to accumulate, store and release $\mathrm{Ca}^{\prime \prime}$ which are intimately concerned with the contraction and relaxation process of muscle (Ebashi, 1961; Hasselbach and Makinose, 1961; Philpott and Goldstein, 1967).

Our histological observations reveal the marked reduction or absence of the $\mathrm{K}^{\prime}$ staining property at the nodes of the alloxan diabetic rat and human diabetic nerve, due presumably to a reduction in the number of polyanionic sites which are normally available for cation binding at the healthy nerve. It is suggested that the relative impermeability of the diffusion barrier of healthy nerve arises when the polyanionic matrix with its electrostatically bound cations serves to exclude the passage of further cations through the mucopolysaccharide substance. The reduction in the availability of cation binding sites is thus likely to be the factor which is responsible for the enhanced permeability of the periaxonal barrier of the diabetic nerve.

A significant thickening of the capillary basement membrane is observed as an ageing phenomenon in both sexes, in both normal and diabetic subjects. Observations on diabetics, however, suggest that the magnitude and incidence of basement membrane thickening increases with the duration of carbohydrate tolerance, thus leading to a significantly greater thickening of the capillary basement membrane in diabetics as compared with healthy subjects of comparable age. Several recent studies (Lazarow and Spiedel, 1964; Srinivasan et al., 1970) have indicated the major differences between the chemical composition of diabetic and healthy glomerular basement membrane. Spiro (1963) and Beisswenger and Spiro (1970) have measured an increase in the glucose content of the diabetic glomerular basement membrane together with an increase in the total amount of basement membrane material. They have also shown that the biosynthesis of glucosamine, which is a prominent component of mucopolysaccharide, from glucose is not under the metabolic regulation of insulin. The activity of general hexokinase 
which phosphorylates glucose to glucose-6phosphate, an intermediate in the synthesis of glucosamine and glucuronic acid, has also been shown to be independent of insulin. Beisswenger and Spiro (1970) believe that glucose metabolized through these pathways independent of insulin results in an accumulation of these macromolecules in the basement membrane substance. They have also shown that the additional glucose in the diabetic glomerular basement membrane is covalently bound as a disaccharide unit to hydroxylysine. It is likely that it is this alteration in the nature of the carbohydrate binding which influences the availability of carboxyl groups for electrostatic binding with metallic cations, and that this may be the important factor responsible for the reduced cation binding property of the mucopolysaccharide gap substance of the Schwann cell basement membrane of diabetic nerve.

Hess and Young (1952) comment that 'until the permeability properties of the cementing disc, perinodal space and outer endoneurium are known it cannot be assumed that at the node there is free diffusion between the axon surface and whatever tissue fluids constitute the external environment of the fibre'. The results of this study provide some information relating to the permeability properties of these paranodal structures in health and in the diabetic state.

This work was supported by grants made to one of us (K.N.S.) by the University of Ceylon, Colombo, and the Wellcome Trust.

\section{REFERENCES}

Adrian, R. H. (1956). The effect of internal and external potassium concentration on the membrane potential of frog muscle. Journal of Physiology, 133, 631-658.

Beisswenger, P. G., and Spiro, R. G. (1970). Human glomerular basement membrane. Chemical alteration in diabetes mellitus. Science, 168, 596-598.

Bishop, G. H. (1932). Action of nerve depressants on potential. Journal of Cellular and Comparative Physiology, 1, 177-194.

Burkel. W. E. (1967). The histological fine structure of perineurium. Anatomical Record, 158, 177-189.

Castaigne, P., Cathala, H.-P., Dry, J., and Mastropaolo, C. (1966). Les réponses des nerfs et des muscles à des stimulations électriques au cours d'une épreuve de garrot ischémique chez l'homme normal et chez le diabétique. Revue Neurologique, 115, 61-66.

Cravioto, H. (1966). The perineurium as a diffusion barrier: ultrastructural correlates. Bulletin of the Los Angeles Neurological Society, 31, 196-208.
Crescitelli, F. (1951). Nerve sheath as a barrier to the action of certain substances. American Journal of Physiology, 166, 229-240.

Ebashi, S. (1961). Calcium binding activity of vesicular relaxing factor. Journal of Biochemistry (Tokyo), 50, 236244.

Feng, T. P., and Gerard, R. W. (1930). Mechanism of nerve asphyxiation: with a note on the nerve sheath as a diffusion barrier. Proceedings of the Society for Experimental Biology (N. Y.) 27, 1073-1076.

Fenn, W. O., and Gerschman, R. (1950). The loss of potassium from frog nerves in anoxia and other conditions. Journal of General Physiology, 33, 195-203.

Frankenhaeuser, B., and Hodgkin, A. L. (1956). The aftereffects of impulses in the giant nerve fibres of Loligo. Journal of Physiology, 131, 341-376.

Gamble, H. J. (1964). Comparative electron-microscopic observations on the connective tissues of a peripheral nerve and a spinal nerve root in the rat. Journal of Anatomy, 98, 17-25.

Gregersen, G. (1968). A study of peripheral nerves in diabetic subjects during ischaemia. Journal of Neurology, Neurosurgery, and Psychiatry, 31, 175-181.

Hasselbach, W., and Makinose, M. (1961). Die Calciumpumpe der 'Erschlaffungsgrana' des Muskels und ihre Abhängigkeit von der ATP Spaltung. Biochemische Zeitschrift, 333, 518-528.

Hess, A., and Young, J. Z. (1952). The nodes of Ranvier. Proceedings of the Royal Society of London B, 140,301-320

Hodgkin, A. L. (1964). The Conduction of the Nervous Impulse. Liverpool University Press: Liverpool.

Huxley, A. F., and Stämpfli, R. (1951). Effect of potassium and sodium on resting and action potentials of single myelinated nerve fibres. Journal of Physiology, 112, 496-508.

Klebanoff, S. J., and Greenbaum, A. L. (1954). The effect of $\mathrm{pH}$ on the diabetogenic action of alloxan. Journal of Endocrinology, 11, 314-322.

Krnjevic, K. (1954). Some observations on perfused fro sciatic nerves. Journal of Physiology, 123, 338-356.

Kuffler, S. W., Nicholls, J. G, and Orkand, R K (1966). Physiological properties of glial cells in the central nervous system of amphibia. Journal of Neurophysiology, 29, 768787.

Landon, D. N., and Langley, O. K. (1969). Cationic binding at the node of Ranvier. Journal of Anatomy, 105, 196.

Landon, D. N., and Langley, O. K. (1971). The local chemical environment of nodes of Ranvier: a study of cation binding. Journal of Anatomy, 108, 419-432.

Langley, O. K. (1969). Ion-exchange at the node of Ranvier. Histochemical Journal, 1, 295-309.

Laurent, T. C., and Ogston, A. G. (1963). The interaction between polysaccharides and other macromolecules. 4 . The osmotic pressure of mixtures of serum albumin and hyaluronic acid. Biochemical Journal, 89, 249-253.

Laurent, T. C., and Pietruszkiewicz, A. (1961). The effect of hyaluronic acid on the sedimentation rate of other substances. Biochimica et Biophysica Acta, 49, 258-264.

Lazarow, A., and Spiedel, E. (1964). The chemical composition of the glomerular basement membrane and its relationship to the production of diabetic complications. In Small Blood Vessel Involvement in Diabetes Mellitus. Edited by M. D. Siperstein, A. R. Colwell, Sr., and K. Meyer. American Institute of Biological Sciences: Washington.

Lieberman, A. R. (1968). The connective tissue elements of the mammalian nodose ganglion. An electron microscope study. Zeitschrift für Zellforschung und mikroskopische Anatomie, 89, 95-111.

Lundberg, A. (1951). Electrotonus in frog spinal roots and sciatic trunk. Acta Physiologica Scandinavica, 23, 234-262. 
Magladery, J. W., McDougal, D. B., Jr., and Stoll, J. (1950) Electrophysiological studies of nerve and reflex activity in normal man. 2. The effects of peripheral ischemia. Bulletin of the Johns Hopkins Hospital, 86, 291-312.

Nathan, P. W. (1958). Ischaemic and post-ischaemic numbness and paraesthesiae. Journal of Neurology, Neurosurgery, and Psychiatry, 21, 12-23.

Ogston, A. G., and Phelps, C. F. (1961). The partition of solutes between buffer solutions and solutions containing hyaluronic acid. Biochemical Journal, 78, 827-833.

Olsson, Y., and Reese, T. S. (1971). Permeability of vasa nervorum and perineurium in mouse sciatic nerve studied by fluorescence and electron microscopy. Journal of Neuropathology and Experimental Neurology, 30, 105-119.

Philpott, C. W., and Goldstein, M. A. (1967). Sarcoplasmic reticulum of striated muscle: Localization of potential calcium binding sites. Science, 155, 1019-1021.

Poole, E. W. (1956). Ischaemic and post-ischaemic paraesthesiae. Normal responses in the upper limb with special reference to the effect of age. Journal of Neurology, Neurosurgery, and Psychiatry, 19, 148-154.

Röhlich, P., and Knoop, A. (1961). Elektronenmicroskopische Untersuchungen an den Hüllen des $\mathrm{N}$. ischiadicus der Ratte. Zeitschrift fiur Zellforschung und Mikroskopische Anatomie, 53, 299-312.

Schubert, M. (1964). Structure of ground substance. In Small Blood Vessel Involvement in Diabetes Mellitus, pp. 221-233. Edited by M. D. Siperstein, A. B. Colwell, and K. Mayer. American Institute of Biological Sciences: Washington.

Seneviratne, K. N. (1972). Permeability of blood nerve barriers in the diabetic rat. Journal of Neurology, Neurosurgery, and Psychiatry, 35, 156-162.

Seneviratne, K. N., and Peiris, O. A. (1968a). The effect of ischaemia on the excitability of human sensory nerve. Journal of Neurology, Neurosurgery, and Psychiatry, 31, 338-347.
Seneviratne, K. N., and Peiris, O. A. (1968b). The effect of ischaemia on the excitability of sensory nerves in diabetes mellitus. Journal of Neurology, Neurosurgery, and Psychiatry, 31, 348-353.

Seneviratne, K. N., and Peiris, O. A. (1969). The effects of hypoxia on the excitability of the isolated peripheral nerves of alloxan-diabetic rats. Journal of Neurology, Neurosurgery, and Psychiatry, 32, 462-469.

Seneviratne, K. N., and Peiris, O. A. (1970). The role of diffusion barriers in determining the excitability of peripheral nerve. Journal of Neurology, Neurosurgery, and Psychiatry, 33, 310-318.

Seneviratne, K. N., Peiris, O. A., and Weerasuriya, A. (1972) Effects of hyperkalaemia on the excitability of peripheral nerve. Journal of Neurology, Neurosurgery, and Psychiatry, 35, 149-155.

Shanes, A. M. (1949). Electrical phenomena in nerve. 1. Squid giant axon. Journal of General Physiology, 33, 57-73.

Shanthaveerappa, T. R., and Bourne, G. H. (1962). The 'perineural epithelium', a metabolically active, continuous, protoplasmic cell barrier surrounding peripheral nerve fasciculi. Journal of Anatomy, 96, 527-537.

Spiro, R. G. (1963). Glycoproteins and diabetes. Diabetes, 12 , 223-230.

Srinivasan, S. R., Berenson, G. S., and Radhakrishnamurthy. B. (1970). Glycoprotein changes in diabetic kidneys. Diabetes, 19, 171-175.

Steiness, I. (1959). Vibratory perception in diabetics during arrested blood flow to the limb. Acta Medica Scandinavica, 163, 195-205.

Thomas, P. K. (1963). The connective tissue of peripheral nerve: an electron microscope study. Journal of Anatomy, 97, 35-44.

Waggener, J. D., Bunn, S. M., and Beggs, J. (1965). The diffusion of ferritin within the peripheral nerve sheath: an electron microscopy study. Journal of Neuropathology and Experimental Neurology, 24, 430-443. 